\title{
artigo
}

\section{Assistência em enfermagem ao paciente cirúrgico com diagnóstico de SARS-COV2: revisão integrativa da literatura}

\author{
Nursing assistance to surgical patients with SARS-COV2 diagnosis: integrative literature review
}

Asistencia de enfermería a pacientes quirúrgicos con diagnóstico de SARS-COV2: revisión integrativa de la literatura

\begin{abstract}
RESUMO
Objetivo: relatar sobre as principais recomendações e cuidados da equipe de saúde frente aos pacientes positivos para Covid-19 durante o período perioperatório. Método:revisão integrativa da literatura com busca em 4 bases de dados sendo elas PubMed, LILACS, MEDLINE ${ }^{\circledR}$, SciELO, utilizando os Descritores de Saúde (DeCS) Coronavírus, Operating Rooms, Nurses, Perioperative Care, Nursing Care. Após a aplicação dos critérios de inclusão, foram selecionados vinte artigos que compuseram a amostra do estudo. Resultados: Devido ao momento de pandemia que o mundo está vivendo, os serviços de saúde tiveram que se moldar de acordo com as recomendações preconizadas. Devem aderir a protocolos visando condutas para prevenção e controle de transmissão do SARS-COV2, nos centros cirúrgicos. Conclusão: mediante aos estudos apresentados as equipes nas unidades cirúrgicas passaram por adaptações. A enfermagem mesmo com os desafios no dia a dia, destaca-se como profissional que visa sempre o cuidado amplo voltado para o bem estar do paciente conectando conhecimento, experiência e empatia.
\end{abstract}

DESCRITORES: Enfermagem, Sars-cov2, Cuidados de Enfermagem, Centro Cirúrgico.

\section{ABSTRACT}

Objective: to report on the main recommendations and care of the health team towards patients positive for Covid-19 during the perioperative period. methods: integrative literature review with search in 4 databases, PubMed, LILACS, MEDLINE ${ }^{\circledR}$, SciELO, using the Health Descriptors (DeCS) Coronavirus, Operating Rooms, Nurses, Perioperative Care, Nursing Care. After applying the inclusion criteria, twenty articles were selected that comprised the study sample. Results: Due to the time of the pandemic that the world is experiencing, health services had to shape themselves according to the recommended recommendations. They must adhere to protocols aimed at conducting prevention and control of transmission of SARS-COV2, in surgical centers. Conclusion: through the studies presented, the teams in the surgical units underwent adaptations. Nursing, even with the challenges on a daily basis, stands out as a professional who always seeks comprehensive care focused on the patient's well-being, connecting knowledge, experience and empathy.

DESCRIPTORS: Nursing, Sars-cov2, Nursing Care, Surgical Center.

\section{RESUMEN}

Informar sobre las principales recomendaciones y cuidados del equipo de salud hacia los pacientes positivos a Covid-19 durante el período perioperatorio. métodos: revisión integradora de la literatura con búsqueda en 4 bases de datos, PubMed, LILACS, MEDLINE ${ }^{\circledR}$, SciELO, utilizando los Descriptores de Salud (DeCS) Coronavirus, Quirófanos, Enfermeras y Enfermeros, Periodo Perioperatorio, Atención de Enfermería. Después de aplicar los criterios de inclusión, se seleccionaron veinte artículos que conformaron la muestra de estudio. Resultados: Debido a la época de la pandemia que vive el mundo, los servicios de salud tuvieron que conformarse de acuerdo con las recomendaciones adoptadas. Deben adherirse a los protocolos destinados a realizar la prevención y el control de la transmisión del SARS-COV2, en los centros quirúrgicos. Conclusión: a través de los estudios presentados, los equipos de las unidades quirúrgicas fueron adaptados. La Enfermería, aún con los desafíos del día a día, se destaca como una profesión que busca siempre una atención integral enfocada al bienestar del paciente, conectando conocimientos, experiencia y empatía.

DESCRIPTORES: Enfermería, Sars-cov2, Atención de Enfermería, Centro Quirúrgico.

RECEBIDO EM: 27/11/2020 APROVADO EM: 10/12/2020 


\title{
Izabella Ventura Borges
}

Enfermeira. Pós graduanda Enfermagem em Centro Cirúrgico da Universidade Federal de Goiás. ORCID: 0000-0002-3869-5552

\author{
Aline de Jesus Bernardes \\ Enfermeira. Pós graduanda Enfermagem em Centro Cirúrgico da Universidade Federal de Goiás. \\ ORCID: 0000-0002-1027-8095
}

\section{Thaís Rodrigues Reis Borges}

Enfermeira. Pós graduanda Enfermagem em Centro Cirúrgico da Universidade Federal de Goiás. ORCID: 0000-0002-4944-2331

\section{Regiane Aparecida dos Santos Soares Barreto}

Enfermeira. Professora Doutora da Universidade Federal de Goiás. ORCID: 0000-0002-7900-6629

\section{INTRODUÇÃO}

0 SARS-COV2 (novo coronavírus), pertence a uma família de vírus que provocam infecções respiratórias. Os primeiros casos da doença foram identificados em dezembro de 2019 na cidade de Wuhan, na China. A doença se espalhou rapidamente pelo país contaminando mais de 80 mil pessoas e cerca de um milhão em todo mundo ${ }^{(1)}$.

O coronavírus causa a doença conhecida como Covid-19, possui alta transmissibilidade e pode manifestar quadros de infecções respiratórias leves e também evoluir para quadros graves. Considera-se o fato de que $80 \%$ da população se apresenta assintomática, 20\% pode necessitar de atendimento hospitalar por apresentar sintomas respiratórios graves, e destes, cerca de 5\% pode necessitar de suporte ventilatório por apresentar insuficiência respiratória ${ }^{(1)}$.

Em 30 de janeiro de 2020, a Organização Mundial de Saúde (OMS) declarou o surto da doença causada por coronavírus como uma emergência de saúde pública de importância internacional. No dia 11 de março de 2020 a Covid-19 foi descrita pela OMS como pandemia ${ }^{(2)}$.

De acordo com a literatura disponível e atual até o momento, a principal via de transmissão é de pessoa para pessoa. Esta pode se dar via gotículas respiratórias, através da tosse ou espirro podendo ser também através do contato direto com pessoas infectadas pelo vírus e por contato indireto em superfícies, objetos ou mãos contaminadas. Outro meio de transmissão estabelecido é por aerossóis, que são gotículas leves produzidas através de procedimentos nos quais ocorre manipulação direta das vias aéreas ${ }^{(1)}$.

O período de incubação pode ser de até 14 dias, tendo em média de 05 a 06 dias, sendo que o vírus SARS-COV2 pode ser detectado e transmitido nos primeiros 03 dias, antes do surgimento dos sintomas ${ }^{(1)}$.

Os sintomas mais comuns apresentados pelo paciente são febre, tosse, coriza, dor de garganta, dispneia, hiporexia (diminuição do apetite), anosmia (perda do olfato), ageusia (perda do paladar), cansaço (astenia) ou fadiga e podem também aparecer sintomas gastrintestinais (náuseas, vômitos, diarreia) ${ }^{(1)}$.

Outros surgimentos clínicos extrapulmonares podem estar associados a infecção por SARS Cov2 como tromboembolismo, alterações cardíacas (arritmias, isquemia miocárdica), alterações renais (hematúria, proteinúria, insuficiência renal), alterações neurológicas (cefaleia, tonturas, encefalopatia, acidente cardiovascular), alterações hepáticas, endócrinas (hiperglicemia, cetoacidose diabética) e alterações dermatológicas (urticária, petéquias, entre outros). O diagnóstico do Covid-19 pode ser realizado através de avaliações clínicas por profissionais da saúde de acordo com os sintomas apresentados pelos pacientes ${ }^{(1)}$.

Se correlacionado com SARS-CoV2, o profissional poderá realizar o pedido do teste RT-PCR por tempo real que diagnostica o coronavírus e também o vírus da influenza, (vírus sincicial respiratório), os exames sorológicos podem ser solicitados para o diagnóstico da Covid-19 e são recomendados à partir do $8^{\circ}$ dia de sintomas sendo eles: Ensaio imunoenzimático (Enzyme-Linked Immunosorbent Assay-ELISA, Imunocromatografia (teste rápido) para detecção de anticorpos, Imunoensaio por Eletroquimioluminescência (ECLIA) e pesquisa de antígenos resultados reagente para SARS-CoV2 pelo método de Imunocromatofragia para detecção de antígeno. E pode ser feito o diagnóstico por imagem para observar alterações pulmonares e confirmar o diagnóstico laboratorial. Para os pacientes assintomáticos são realizados RT-PCR e teste imunológico com resultados para IgM $\backslash \operatorname{IgA}$ para verificar a presença de anticorpos ${ }^{(1)}$.

Segundo o boletim epidemiológico do Ministério da Saúde de dezembro de 2020 , foram notificados 1.724 .815 casos suspeitos de síndrome gripal de covid-19 em profissionais da saúde. Destes, 406.803 $(23,6 \%)$ foram confirmados para covid-19, números que representam cerca de $7 \%$ do número total de casos confirmados no Brasil ${ }^{(21)}$.

Em meio à pandemia existente, atendimentos e procedimentos em saúde passaram por mudanças. Os procedimentos cirúrgicos eletivos foram afetados por interferências em suas realizações. Cancelamentos, priorizações e realização de inovação das práticas através de novos protocolos elaborados e modificados em todo o tempo ${ }^{(3)}$.

Apesar de a Covid-19 ser uma doença 


\section{artigo}

nova, já é possível encontrar estudos publicados, porém as recomendações ao perioperatório são escassas ${ }^{(5)}$.

Diante dessas considerações, torna-se importante estudos que direcionem os profissionais a segurança ocupacional e dos pacientes e questiona-se nesta pesquisa: Quais os cuidados necessários para a assistência de enfermagem ao paciente positivo para covid-19 no centro cirúrgico?

Esse estudo tem como objetivo relatar sobre as principais recomendações e cuidados que a equipe de saúde deverá implementar frente aos pacientes positivos para Covid-19 durante o período perioperatório.

\section{MÉTODO}

Trata-se de um estudo bibliográfico, realizada por meio de uma revisão integrativa da literatura, método que tem como propósito associar e resumir resultados de pesquisa de um determinado tema ou questão, com a finalidade de metodizar e organizar, colaborando para aprofundamento do estudo investigado. Esse modelo de pesquisa permite sintetizar vários estudos publicados, possibilitando resultados gerais dos aspectos particulares da dimensão de cada estudo ${ }^{(6)}$.

A revisão integrativa é dividida em etapas sendo elas: $1^{\text {a }}$ etapa: Definir a pergunta da revisão; $2^{a}$ etapa: Busca de seleção de artigos primários; $3^{a}$ etapa: Extração de dados de estudos; $4^{a}$ etapa: Avaliação crítica dos estudos primários; $5^{\mathrm{a}}$ etapa: Síntese dos resultados da revisão; $6^{a}$ etapa: Apresentação da Revisão ${ }^{(6)}$.

Para a construção e evolução da revisão integrativa foi elaborada a seguinte pergunta norteadora: Quais são os cuidados de enfermagem necessários para atender pacientes com a Covid-19? Para o desenvolvimento da pergunta norteadora foi utilizado o formato PICo sendo: P- pacientel enfermeiro, I- pacientes com a Covid19 e cuidados de enfermagem ${ }^{(6)}$.

A coleta de artigos foi realizada durante os meses de abril a dezembro de 2020, por meio da Biblioteca Virtual em Saúde cujas bases de dados foram: National Library of
Medicine National Institutes of Health (PubMed), a Literatura Latino-Americana e do Caribe em Ciências da Saúde (LILACS), Medical Analysis Retrieval System Online (MEDLINE ${ }^{\circ}$ ), Scientific Eletronic Library Online (SciELO). Foram utilizados os Descritores de Saúde (DeSC): Coronavírus, Operating Room, Nurse, Perioperative, safety. Constituíram como critérios de inclusão artigos originais, publicados entre os anos de 2019 a 2020, utilizando artigos em língua portuguesa e inglesa. Realizado busca em livros e documentos publicados pelo Ministério da Saúde e órgãos competentes relacionados.

\section{RESULTADOS}

Após o término da pesquisa os autores realizaram uma leitura crítica reflexiva. Foi realizado um rodízio das leituras de forma que os artigos e documentos foram lidos por todos os autores. Para sistematizar o percurso metodológico, foi utilizado fluxograma Prisma (Quadro 1) e incluídos os estudos que contemplaram os seguintes critérios de inclusão: artigos voltados a responder o objetivo da pesquisa, revisão de literatura, com informações relevantes que abordassem a influência da assistência de enfermagem no centro cirúrgico e relatos de experiências de acordo com o contexto.
Procedeu-se a leitura minuciosa de cada artigo, destacando 21 artigos e documentos que responderam ao objetivo proposto por este estudo e que foram selecionados e referenciados no presente texto.

Segundo os critérios ressalta-se que foram excluídos 2 artigos e documentos que se apresentavam duplicados e que após leitura na íntegra não estavam adequados com a temática.

\section{DISCUSSÃO}

\section{Preparo e Desinfecção de Sala Ope- ratória}

Devido ao momento de pandemia que o mundo está vivendo, os serviços de saúde tiveram que se moldar de acordo com as recomendações preconizadas. $\mathrm{O}$ centro cirúrgico passou por algumas adaptações, dando prioridade para procedimentos de urgência/emergência e reavaliando a necessidade das cirurgias eletivas. Para receber estes pacientes é necessário que haja um boa comunicação entre as equipes, os profissionais devem seguir os protocolos de cirurgia segura, utilizar os checklists próprios para o procedimento, como os de paramentação e desparamentação, recomenda-se que todos os profissionais que forem participar do ato cirúrgico estejam devidamente paramentados, utilizando os EPI preconizados e pro-

\section{Figura 1: Fluxograma do percurso metodológico.}

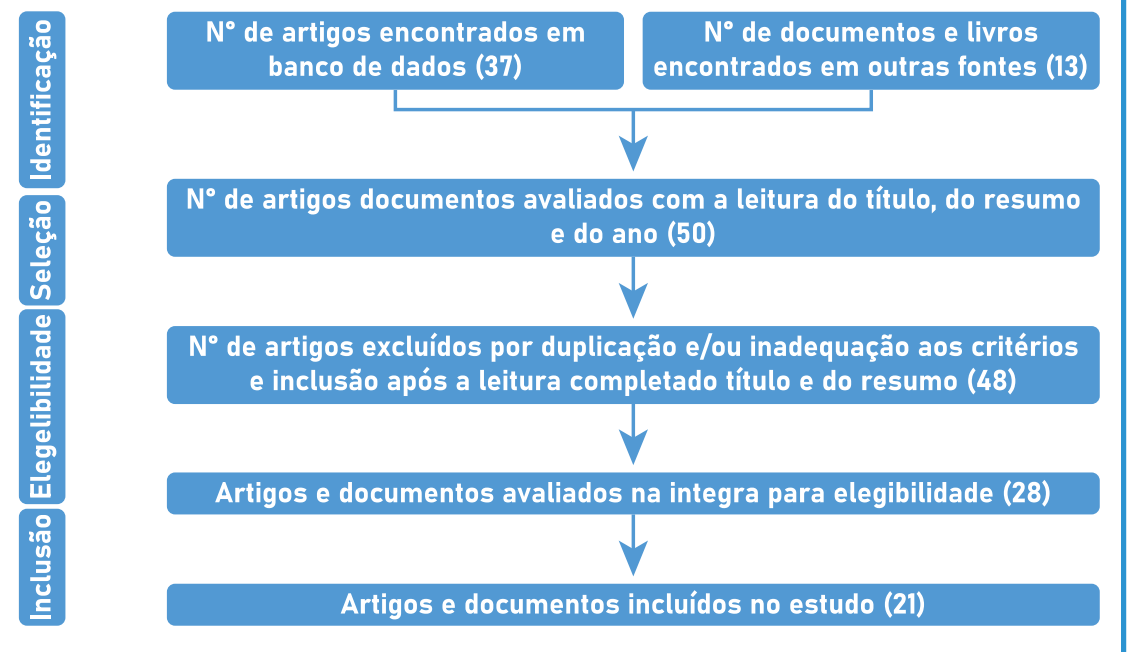

Fonte: Elaborado pelos autores. 
Quadro 1. Características dos 21 estudos encontrados na revisão integrativa.

\begin{tabular}{|c|c|c|c|c|}
\hline AUTORES & ARTIGOS & OBJETIVO & RECOMENDAÇÕES & CONCLUSÃO \\
\hline $\begin{array}{l}\text { COIMBRA, R; } \\
\text { EDWARDS, S; KU- } \\
\text { RIHARA, H; BASS, G } \\
\text { A; BALOGH, ZSOLT J; } \\
\text { TILSED, J; FACCINCA- } \\
\text { NI, R; CARLUCCI, M; } \\
\text { MARTINEEZ CASAS, } \\
\text { I; GAARDER, C; TA- } \\
\text { BUENCA, A; COIM- } \\
\text { BRA, BO C; MARZI, I. }\end{array}$ & $\begin{array}{l}\text { European Society of } \\
\text { Trauma and Emer- } \\
\text { gency Surgery (ESTES) } \\
\text { recommendations for } \\
\text { trauma and emergen- } \\
\text { cy surgery prepara- } \\
\text { tion during times of } \\
\text { COVID-19 infection }\end{array}$ & $\begin{array}{l}\text { Informar os cuidados } \\
\text { necessários para pa- } \\
\text { cientes de trauma e } \\
\text { cirúrgicos em tempos } \\
\text { de pandemia }\end{array}$ & $\begin{array}{l}\text { Recomendam oito domínios: } \\
\text { Recomendação geral para Serviços } \\
\text { cirúrgicos; Cirurgia de Emergên- } \\
\text { cia para pacientes com suspeita } \\
\text { positiva ou suspeita de COVID-19 } \\
\text { em estado crítico - Planejamento } \\
\text { pré-operatório e seleção de casos; } \\
\text { Configuração da sala de cirurgia; } \\
\text { Transporte do paciente para a sala } \\
\text { de cirurgia; Preparação da equipe } \\
\text { cirúrgica; Considerações anes- } \\
\text { tésicas; Abordagem cirúrgica; e } \\
\text { Conclusão do caso. }\end{array}$ & $\begin{array}{l}\text { As recomendações } \\
\text { realçam a importância } \\
\text { de o profissional estar } \\
\text { preparado para o aten- } \\
\text { dimento independente } \\
\text { da situação realizando } \\
\text { um atendimento com } \\
\text { segurança. }\end{array}$ \\
\hline $\begin{array}{l}\text { MENDES KDS, } \\
\text { SILVEIRA RCCP, } \\
\text { GALVÃO CM. }\end{array}$ & $\begin{array}{l}\text { Uso de gerenciador } \\
\text { de referências } \\
\text { bibliográficas na } \\
\text { seleção dos estudos } \\
\text { primários em revisão } \\
\text { integrativa. }\end{array}$ & $\begin{array}{l}\text { Apresentar o uso } \\
\text { do gerenciador de } \\
\text { referências para } \\
\text { auxiliar na construção } \\
\text { de banco de dados e } \\
\text { seleção de estudos } \\
\text { primários. }\end{array}$ & $\begin{array}{l}\text { Demonstra a busca através do } \\
\text { gerenciador com recursos para } \\
\text { auxiliar na construção de uma } \\
\text { revisão integrativa. }\end{array}$ & $\begin{array}{l}\text { O uso da tecnologia } \\
\text { auxilia no resultado } \\
\text { deste tipo de estudo, } \\
\text { assegurando uma } \\
\text { melhoria na qualidade. }\end{array}$ \\
\hline $\begin{array}{l}\text { WONG J, GOH QY, } \\
\text { TAN Z, LIE SA, TAY YC, } \\
\text { YI NG S, SOH CR }\end{array}$ & $\begin{array}{l}\text { Preparing for a } \\
\text { COVID-19 pandemic: } \\
\text { a review of operating } \\
\text { room outbreak res- } \\
\text { ponse measures in a } \\
\text { large tertiary hospital } \\
\text { in Singapore }\end{array}$ & $\begin{array}{c}\text { Demonstrar sobre } \\
\text { que a preparação } \\
\text { para uma pandemia } \\
\text { exige que o hospital } \\
\text { desenvolva estraté- } \\
\text { gias para gerenciar } \\
\text { sua infraestrutura, } \\
\text { processos, equipe e } \\
\text { pacientes. }\end{array}$ & $\begin{array}{l}\text { Relata as medidas que foram toma- } \\
\text { das através da equipe de engenha- } \\
\text { ria, administrativa e multiprofissio- } \\
\text { nal de um Hospital especialista em } \\
\text { cuidados agudos, para os cuidados } \\
\text { aos pacientes e profissionais. }\end{array}$ & $\begin{array}{l}\text { Relata como foi impor- } \\
\text { tante avaliar a viabili- } \\
\text { dade de modificações } \\
\text { completamente novas na } \\
\text { sala de cirurgia ou de um } \\
\text { novo fluxo de trabalho } \\
\text { para continuidade dos } \\
\text { atendimentos. }\end{array}$ \\
\hline $\begin{array}{l}\text { KANG Y, DENG L, } \\
\text { ZHANG D, WANG } \\
\text { Y,WANG G, MEI L, } \\
\text { ZHOU G, SHU H }\end{array}$ & $\begin{array}{l}\text { A practice of anesthe- } \\
\text { sia scenario design for } \\
\text { emergency cesarean } \\
\text { section in patients } \\
\text { with COVID-19 infec- } \\
\text { tion based on the role } \\
\text { of standard patient }\end{array}$ & $\begin{array}{l}\text { Prestar uma assis- } \\
\text { tência segura no } \\
\text { cenário das cesaria- } \\
\text { nas, prevenindo de } \\
\text { infecção cruzada e } \\
\text { melhorar o fluxo de } \\
\text { trabalho. }\end{array}$ & $\begin{array}{l}\text { Apresenta a prática e experiência } \\
\text { para planejar um programa de trei- } \\
\text { namento em um centro cirúrgico. } \\
\text { Com as definições: Estabelecimento } \\
\text { de equipe, Estabelecimento regra } \\
\text { cirúrgica e fluxo de trabalho, Cenário } \\
\text { da anestesia. }\end{array}$ & $\begin{array}{l}\text { O estudo demonstrou } \\
\text { que é necessário ter uma } \\
\text { comunicação uniforme } \\
\text { na equipe e realizar trei- } \\
\text { namentos e práticas re- } \\
\text { petidas para uma melhor } \\
\text { prática em cirurgias com } \\
\text { pacientes com COVID19 }\end{array}$ \\
\hline $\begin{array}{l}\text { LOCKHART, S L; DU- } \\
\text { GGAN, L V; GROCOTT, } \\
\text { HP; }\end{array}$ & $\begin{array}{l}\text { Personal protective } \\
\text { equipment (PPE) } \\
\text { for both anesthe- } \\
\text { siologists and other } \\
\text { airway managers: } \\
\text { principles and practice } \\
\text { during the COVID } 19 \\
\text { pandemic } \\
\end{array}$ & $\begin{array}{l}\text { Demonstrar a } \\
\text { prioridade no uso do } \\
\text { EPI na prevenção dos } \\
\text { profissionais na luta } \\
\text { contra a COVID19. } \\
\text { Enfatizando a impor- } \\
\text { tância do treinamen- } \\
\text { to da equipe. } \\
\end{array}$ & $\begin{array}{c}\text { Recomendam três níveis para o } \\
\text { EPI: Precauções contra gotículas } \\
\text { e contatos; Precauções aerossóis, } \\
\text { gotículas e contato; Precauções } \\
\text { aerossóis, gotículas e contatos para } \\
\text { procedimentos médicos geradores } \\
\text { de Aerossóis }\end{array}$ & $\begin{array}{l}\text { O artigo conclui a } \\
\text { necessidade de ofere- } \\
\text { cer serviços de saúde } \\
\text { seguros, conservando } \\
\text { EPI adequados. }\end{array}$ \\
\hline $\begin{array}{l}\text { SEAN COFF EY, } \\
\text { ANOUSKA MOYNA- } \\
\text { GH, BELINDA GREEN, } \\
\text { JOHN EDMOND, } \\
\text { GERARD T WILKINS, } \\
\text { BRENDAN ARNOLD, } \\
\text { JAMES PEMBERTON, } \\
\text { BEN WILKINS, MI- } \\
\text { CHAEL JA WILLIAMS }\end{array}$ & $\begin{array}{l}\text { Changes to manage- } \\
\text { ment of a non-pande- } \\
\text { mic illness during the } \\
\text { COVID-19 pandemic: } \\
\text { case study of invasive } \\
\text { management of acute } \\
\text { coronary syndrome }\end{array}$ & $\begin{array}{c}\text { Demonstrar os riscos } \\
\text { e benefícios apresen- } \\
\text { tados pela COVID19, } \\
\text { em pacientes com } \\
\text { tratamento da sín- } \\
\text { drome coronariana } \\
\text { aguda. }\end{array}$ & $\begin{array}{l}\text { Aponta riscos de COVID19 em } \\
\text { pacientes com síndromes, risco } \\
\text { para os profissionais e manejo com } \\
\text { os pacientes. }\end{array}$ & $\begin{array}{l}\text { Demonstram o provável } \\
\text { aumento de complica- } \\
\text { ções cardiovasculares } \\
\text { contra o risco da CO- } \\
\text { VID19 e que as estimati- } \\
\text { vas de riscos e benefícios } \\
\text { poderá ser útil nas } \\
\text { tomadas de decisões. }\end{array}$ \\
\hline
\end{tabular}




\section{artigo}

\begin{tabular}{|c|c|c|c|c|}
\hline $\begin{array}{l}\text { GALLASCH, } \\
\text { CH; CUNHA, } \\
\text { ML; LASP,LAS; } \\
\text { JUNIOR, JSS; }\end{array}$ & $\begin{array}{l}\text { Prevenção relacionada } \\
\text { à exposição ocupacio- } \\
\text { nal do profissional de } \\
\text { saúde no cenário de } \\
\text { COVID-19 }\end{array}$ & $\begin{array}{l}\text { Descrever ações de } \\
\text { proteção ao profissio- } \\
\text { nal exposto a COVID19 }\end{array}$ & $\begin{array}{l}\text { Realiza uma revisão sobre os } \\
\text { impactos da COVID } 19 \text { nas unidades } \\
\text { de saúde, as falhas de proteção dos } \\
\text { trabalhadores nos atendimentos e } \\
\text { expõe a necessidade de dispor de EPI } \\
\text { e monitorar profissionais expostos. }\end{array}$ & $\begin{array}{l}\text { Conclui que os cuidados } \\
\text { na promoção da saúde } \\
\text { deverão ser prioridade. Os } \\
\text { EPI's devem ser suficiente } \\
\text { para todos os trabalha- } \\
\text { dores e somados com } \\
\text { treinamentos para seu } \\
\text { uso correto. }\end{array}$ \\
\hline $\begin{array}{l}\text { MARQUES } \\
\text { LC, LUCCA DC, } \\
\text { ALVES EO, FER- } \\
\text { NANDES GCM, } \\
\text { NASCIMENTO } \\
\text { KC. }\end{array}$ & $\begin{array}{l}\text { COVID-19: Cuidados } \\
\text { de enfermagem para } \\
\text { segurança no aten- } \\
\text { dimento de serviço } \\
\text { pré-hospitalar móvel }\end{array}$ & $\begin{array}{l}\text { Descrever as ações } \\
\text { realizadas por en- } \\
\text { fermeiros do serviço } \\
\text { pré-hospitalar móvel } \\
\text { antes, durante e após } \\
\text { atendimentos e trans- } \\
\text { ferências de pacientes } \\
\text { suspeitos e/ou confir- } \\
\text { mados para Covid-19. }\end{array}$ & $\begin{array}{l}\text { Demonstra as limitações encontra- } \\
\text { das por profissionais de enfermagem } \\
\text { para diminuir a exposição à doença. }\end{array}$ & $\begin{array}{l}\text { Identificou a preocupação } \\
\text { com a segurança dos } \\
\text { profissionais e pacientes, } \\
\text { uma vez que adotaram } \\
\text { condutas para a preven- } \\
\text { ção e controle da pande- } \\
\text { mia mediante a utilização } \\
\text { de equipamentos, o o } \\
\text { preparo da ambulância. }\end{array}$ \\
\hline OLIVEIRA, PCC & $\begin{array}{l}\text { Pandemia do novo } \\
\text { coronavírus (SARS- } \\
\text {-CoV-2): panorama do } \\
\text { enfrentamento dos } \\
\text { profissionais de enfer- } \\
\text { magem no controle de } \\
\text { infecção pela doença } \\
\text { COVID-19 no Brasil }\end{array}$ & $\begin{array}{l}\text { Orientar sobre os } \\
\text { cuidados que os pro- } \\
\text { fissionais de enferma- } \\
\text { gem estão tendo para } \\
\text { controle de infecção } \\
\text { pelo vírus. }\end{array}$ & $\begin{array}{c}\text { Aponta os equipamentos de proteção } \\
\text { individual que devem ser utilizados } \\
\text { e os cuidados mínimos a serem } \\
\text { adotados. }\end{array}$ & $\begin{array}{l}\text { Evidencia o cuidado que os } \\
\text { profissionais de enfer- } \\
\text { magem devem ter, e a } \\
\text { importância da formação } \\
\text { de novos profissionais. }\end{array}$ \\
\hline $\begin{array}{l}\text { BRASIL, MINIS- } \\
\text { TÉRIO DA SAÚDE }\end{array}$ & $\begin{array}{c}\text { Protocolo de Manejo } \\
\text { Clínico para o Novo } \\
\text { Coronavírus (2019- } \\
\text { nCoV) }\end{array}$ & $\begin{array}{c}\text { Orientar na atuação na } \\
\text { identificaçãa, notifica- } \\
\text { ção e manejo oportuno } \\
\text { de casos suspeitos } \\
\text { pelo Novo Coronavirus } \\
\text { de modo a mitigar os } \\
\text { riscos de transmissão } \\
\text { sustentada no território } \\
\text { nacional. }\end{array}$ & $\begin{array}{l}\text { Instrui a evitar a transmissão do vírus } \\
\text { para profissionais de saúde e conta- } \\
\text { tos próximos, as condutas frente aos } \\
\text { casos. }\end{array}$ & $\begin{array}{c}\text { Corrobora com definições, } \\
\text { atendimento e tratamento } \\
\text { e medidas de controle } \\
\text { para os profissionais da } \\
\text { saúde. }\end{array}$ \\
\hline ANVISA & $\begin{array}{c}\text { NOTA TÉCNICA } \\
\text { GVIMS/GGTES/ANVI- } \\
\text { SA No 06/2020 }\end{array}$ & $\begin{array}{l}\text { Orientaç̧̃̃es para a } \\
\text { prevenção e o controle } \\
\text { das infecções pelo novo } \\
\text { coronavírus (SARS- } \\
\text {-COV-2) em procedi- } \\
\text { mentos cirúrgicos - }\end{array}$ & $\begin{array}{l}\text { Discrimina a composição da sala e } \\
\text { equipe, uso de EPI, uso de aparelhos } \\
\text { laparingoscópicos e a retomada das } \\
\text { cirurgias eletivas. }\end{array}$ & $\begin{array}{l}\text { Expõe informações para } \\
\text { auxiliar os profissionais } \\
\text { nos procedimentos cirúr- } \\
\text { gicos. }\end{array}$ \\
\hline ANVISA & $\begin{array}{l}\text { NOTA TÉCNICA } \\
\text { GVIMS/GGTES/ANVI- } \\
\text { SA Nº } 04 / 2020\end{array}$ & $\begin{array}{l}\text { Orientar quanto as } \\
\text { medidas de prevenção } \\
\text { e controle durante a } \\
\text { assistência aos casos } \\
\text { suspeitos e confir- } \\
\text { mados de infecção ao } \\
\text { coronavírus }\end{array}$ & $\begin{array}{l}\text { Orienta cuidados no atendimento pré } \\
\text { hospitalar, triagem e durante a as- } \\
\text { sistência hospitalar. Medidas de pre- } \\
\text { caução e isolamento, cuidados com } \\
\text { resíduos e higienização hospitalar. }\end{array}$ & $\begin{array}{l}\text { Apresenta medidas para } \\
\text { o atendimento visando o } \\
\text { cuidado com os profis- } \\
\text { sionais que assistem } \\
\text { o paciente suspeito ou } \\
\text { confirmado. }\end{array}$ \\
\hline ANVISA & $\begin{array}{l}\text { NOTA TÉCNICA } \\
\text { GVIMS/GGTES/ANVI- } \\
\text { SA Nº 07/2020 }\end{array}$ & $\begin{array}{l}\text { Orientações para } \\
\text { prevenção e vigilância } \\
\text { epidemiológica das in- } \\
\text { fecções por sars-cov-2 } \\
\text { (covid-19) dentro dos } \\
\text { serviços de saúde. }\end{array}$ & $\begin{array}{c}\text { Conduz uma temática a respeito do } \\
\text { contexto da doença, monitoramento } \\
\text { dos casos suspeitos, ações a serem } \\
\text { realizada com profissionais da saúde } \\
\text { e o uso de EPI. }\end{array}$ & $\begin{array}{c}\text { Expõe o cuidado e atenção } \\
\text { aos profissionais e ações } \\
\text { a serem seguidas frente a } \\
\text { exposição do trabalhador } \\
\text { a Covid19. }\end{array}$ \\
\hline
\end{tabular}




\begin{tabular}{|c|c|c|c|c|}
\hline $\begin{array}{l}\text { BRASIL, MI- } \\
\text { NISTÉRIO DA } \\
\text { SAÚDE }\end{array}$ & $\begin{array}{l}\text { GUIA PRÁTICO DE } \\
\text { GESTÃO EM SAÚDE } \\
\text { NO TRABALHO PARA } \\
\text { COVID-19 }\end{array}$ & $\begin{array}{l}\text { Orientações para Médicos } \\
\text { do Trabalho e gestores } \\
\text { na adoção de medidas } \\
\text { protetivas de prevenção } \\
\text { dos trabalhadores quanto } \\
\text { a prevenção, investigação, } \\
\text { condutas após contágio. }\end{array}$ & $\begin{array}{l}\text { Explana as medidas preventivas e } \\
\text { educativas, cuidados com o trabalha- } \\
\text { dor exposto ao vírus, afastamento e } \\
\text { retorno ao trabalho. }\end{array}$ & $\begin{array}{c}\text { Norteia informações para } \\
\text { auxliar na segurança à } \\
\text { saúde do trabalhador e } \\
\text { do ambiente de trabalho. }\end{array}$ \\
\hline $\begin{array}{l}\text { ORGANIZA- } \\
\text { ÇÃO PAN-A- } \\
\text { MERICANA DA } \\
\text { SAÚDE }\end{array}$ & OPAS & $\begin{array}{c}\text { Materiais de comunicação } \\
\text { baseados em evidências }\end{array}$ & - & $\begin{array}{c}\text { Informa sobre os riscos a } \\
\text { saúde apresentado pela } \\
\text { covid. }\end{array}$ \\
\hline SOBECC & 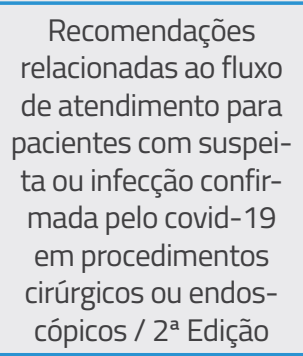 & $\begin{array}{l}\text { Demonstrar o manejo dos } \\
\text { casos suspeitos e confir- } \\
\text { mados dentro do setor } \\
\text { centro cirúrgico. }\end{array}$ & $\begin{array}{l}\text { Disponibiliza orientações a respeito } \\
\text { do atendimento de casos, visando } \\
\text { a proteção da equipe, organização } \\
\text { do fluxo de atendimento, preparo da } \\
\text { sala e cuidados com materiais. }\end{array}$ & $\begin{array}{l}\text { Recomenda ações com } \\
\text { objetivo de garantir a } \\
\text { segurança e instrumen- } \\
\text { talizar os profissionais. }\end{array}$ \\
\hline $\begin{array}{l}\text { A.C.CAMAR- } \\
\text { GO CANCER } \\
\text { CENTER }\end{array}$ & $\begin{array}{l}\text { Orientações em casos } \\
\text { suspeitos ou confir- } \\
\text { mados de infecção por } \\
\text { Covid-19. }\end{array}$ & $\begin{array}{l}\text { Materiais de orientação a } \\
\text { casos suspeitos e confir- } \\
\text { mados }\end{array}$ & - & $\begin{array}{c}\text { Cita orientações para } \\
\text { atendimento para casos } \\
\text { confirmas ou suspeitos. }\end{array}$ \\
\hline CBC & $\begin{array}{l}\text { Orientações para o } \\
\text { retorno de cirurgias } \\
\text { eletivas durante a } \\
\text { pandemia de CO- } \\
\text { VID-19 }\end{array}$ & $\begin{array}{l}\text { Orientar gestores e médi- } \\
\text { cos na retomada de cirur- } \\
\text { gias eletivas, apontando } \\
\text { pontos a serem discutidos } \\
\text { para maior segurança do } \\
\text { profissional e paciente. }\end{array}$ & $\begin{array}{l}\text { Aponta critérios para discussão e } \\
\text { avaliação das novas necessida- } \\
\text { des, estratégias de prevenção de } \\
\text { contagio. }\end{array}$ & $\begin{array}{c}\text { Explana orientações para } \\
\text { médicos e serviços de } \\
\text { saúde na retomada das } \\
\text { cirurgias. }\end{array}$ \\
\hline $\begin{array}{l}\text { UNIVERSIDA- } \\
\text { DE FEDERAL } \\
\text { DE CAMPINA } \\
\text { GRANDE } \\
\text { HOSPITAL } \\
\text { UNIVERSI- } \\
\text { TÁRIO JÚLIO } \\
\text { BANDEIRA DE } \\
\text { MELLO }\end{array}$ & $\begin{array}{l}\text { PARAMENTAÇÃO E } \\
\text { DESPARAMENTACÃO } \\
\text { NO ATENDIMENTO } \\
\text { À PACIENTES COM } \\
\text { SUSPEITA/CONFIR- } \\
\text { MAÇÃO DE COVID-19 }\end{array}$ & $\begin{array}{l}\text { Padronizar o processo de } \\
\text { paramentação e despa- } \\
\text { ramentação dos Equipa- } \\
\text { mentos de Proteção Indi- } \\
\text { vidual (EPIs) utilizados no } \\
\text { atendimento aos pacien- } \\
\text { tes suspeitos/confirmados } \\
\text { de COVID } 19 \text { no âmbito do } \\
\text { Hospital Universitário Júlio } \\
\text { Bandeira. }\end{array}$ & $\begin{array}{c}\text { Através de fluxogramas demonstra } \\
\text { os processos de atendimento aos } \\
\text { pacientes suspeitos e confirmados } \\
\text { de COVID. }\end{array}$ & $\begin{array}{l}\text { Destaca sobre a impor- } \\
\text { tância da higienização } \\
\text { correta das mãos e a utili- } \\
\text { zação dos equipamentos } \\
\text { de proteção individuais } \\
\text { para prevenção de conta- } \\
\text { gio pelo vírus. }\end{array}$ \\
\hline POSSARI, JF & $\begin{array}{l}\text { Centro Cirúrgico: } \\
\text { Planejamento, Orga- } \\
\text { nização e Gestão. } 5^{\text {a }} \\
\text { edição. }\end{array}$ & $\begin{array}{l}\text { Capítulos voltados a infra } \\
\text { estrutura, gestão pessoal } \\
\text { e cuidados no serviço de } \\
\text { saúde. }\end{array}$ & $\begin{array}{l}\text { Aborda temas da infra estrutura, } \\
\text { dimensionamento de enfermagem, } \\
\text { gerenciamento de cirurgias. }\end{array}$ & $\begin{array}{l}\text { Apresenta conteú- } \\
\text { dos amplos de centro } \\
\text { cirúrgico visando desde a } \\
\text { montagem de uma sala } \\
\text { até os cuidados e tarefas } \\
\text { a serem realizados. }\end{array}$ \\
\hline $\begin{array}{l}\text { BRASIL, MI- } \\
\text { NISTÉRIO DA } \\
\text { SAÚDE }\end{array}$ & $\begin{array}{l}\text { BOLETIM EPIDEMIO- } \\
\text { LÓGICO ESPECIAL. } \\
\text { Doença pelo Corona- } \\
\text { vírus COVID-19 }\end{array}$ & $\begin{array}{l}\text { Infomar a análise dos } \\
\text { dados epidemiológicos da } \\
\text { covid no Brasil }\end{array}$ & - & $\begin{array}{c}\text { Demonstra dados, esta- } \\
\text { tísticas de casos, óbitos e } \\
\text { vigilância laboratorial no } \\
\text { Brasil. }\end{array}$ \\
\hline
\end{tabular}

põe-se que apenas uma sala operatória seja destinada para receber estes pacientes ${ }^{(3)}$.

Sendo assim a Associação Brasileira de
Enfermeiros de Centro Cirúrgico, Recuperação Anestésica e Centro de Material e Esterilização (SOBECC) recomenda que o profissional que for montar a sala operatória $(\mathrm{SO})$ deve higienizar as mãos antes de começar e verificar com a equipe da enge- 
nharia clínica ou da manutenção hospitalar a pressão que a sala se encontra e sua configuração. A porta da sala cirúrgica deve estar sinalizada sobre os tipos de precauções para contatos e aerossóis. Sendo assim recomenda-se deixar na $\mathrm{SO}$ somente o que for usar e se possível utilizar materiais descartáveis, para facilitar a limpeza e desinfecção tanto dos instrumentais como da sala ${ }^{(7)}$.

Durante o procedimento de intubação e extubação recomenda-se que apenas a equipe de anestesiologia permaneça dentro da $\mathrm{SO}$ e que o restante da equipe aguarde do lado de fora, para minimizar os riscos de contaminação com vírus durante o procedimento. A sala deverá estar em pressão negativa, e durante o ato cirúrgico recomenda-se restringir um quantitativo de profissionais. Sendo assim, se possível ter um profissional de apoio do lado de fora da SO, para suporte e auxilio na prevenção e utilização das técnicas necessárias. As equipes devem redobrar os cuidados com objetos pessoais, quanto à utilização do aparelho de celular, devem ser orientados sobre o uso destes objetos e seguir as orientações recomendadas pelos serviços de saúde ${ }^{(3)}$. Redução do parágrafo

Após o procedimento cirúrgico de pacientes com suspeita ou confirmado para covid-19, a SO deve ser desmontada e higienizada. Os filtros e os circuitos devem ser trocados, deve ser feita a desinfecção dos materiais de anestesia, deve se proceder a limpeza terminal de todos os equipamentos e mobiliários da SO, o profissional tem que estar paramentado e utilizando os EPI para as precauções de contato e aerossóis ${ }^{(7)}$.

Os produtos orientados para fazer a limpeza são aqueles a base de quaternário de amônia elou hipoclorito de sódio, durante a higienização da sala a pressão da mesma deve se manter negativa. Sugere que se tenha um tempo de pelo menos 1 hora de um procedimento cirúrgico por outro para que se tenha tempo para fazer a limpeza e descontaminação da sala. $\mathrm{O}$ profissional responsável deve se atentar na hora da retirada dos EPI para evitar uma possível contaminação pelo vírus, todo lixo infectante deve ser descartado em um saco branco leitoso, e não aproveitar nenhum medicamento e materiais que sobraram, recomenda se descartar ${ }^{(7)}$.

\section{Recomendação de Paramentação e Desparamentação}

Ainda não se conhecem todos os mecanismos de transmissão da Covid-19, o que torna as medidas de prevenção social e entre os profissionais da saúde difíceis de serem implementadas. Os profissionais da saúde estão na linha de frente no tratamento e orientação da população exposta ou infectada. É reconhecido que o vírus se propaga por aerossóis de secreçôes respiratórias, principalmente de pacientes sintomáticos, nos quais a carga viral tende a ser maior ${ }^{(8)}$.

Profissionais que trabalham em setores com pacientes críticos ou na manipulação de vias aéreas de portadores do vírus, certamente são os mais expostos dentro do hospital, e devem utilizar os equipamentos de proteção individual corretamente na sua paramentação e principalmente no momento de desparamentação. Também é imprescindível que a equipe de enfermagem comunique a todos os profissionais que irão participar do ato cirúrgico do paciente para que se paramentem, o paciente deve ser avisado de todo procedimento cirúrgico, ser recepcionado pelo enfermeiro e já transportado para a SO, deve-se ficar atento quanto aos sinais vitais do paciente, controle rigoroso da temperatura, oxigenaçã̃o ${ }^{(8,9)}$.

Como toda a rotina do centro cirúrgico será alterada, caso haja pacientes com suspeita ou infectados, deve ser realizado um treinamento adequado a toda equipe que presta assistência, deve ser feito um modelo de checklist e uma checagem sistemática, esse deve ficar de forma acessível e em áreas dedicadas para paramentação e desparamentação. Recomenda-se que toda a equipe passe por treinamentos para paramentação e desparamentação ${ }^{(10)}$.

Na preparação de uma SO para receber um paciente infectado ou com suspeita, deve-se separar somente o que for indispensável de ficar dentro da sala, assim, poucos materiais necessitarão ser desinfetados, reprocessados ou descartados ao término do procedimento. Priorizar os materiais descartáveis e todos os equi- pamentos que são tocados por muitas pessoas devem ser cobertos com plástico sendo esses monitores, aparelhos de anestesia, aparelhos de ventilação mecânica, aparelhos de ultrassom, aparelhos de raio $\mathrm{x}$, aparelhos de procedimentos de vídeos, computadores, entre outros, realizando desinfecção terminal depois de finalizado o procedimento cirúrgico ${ }^{(10)}$.

É recomendado que EPI seja disponível para os profissionais, a adoção de medidas para prevenção de contato com aerossóis, mascaras N95 para o procedimento cirúrgico, devido possíveis dispersão de aerossóis, uniforme privativo do centro cirúrgico, capotes descartável impermeável de mangas longas, luvas, tocas, óculos, máscara face shield e botas impermeáveis. Todos os profissionais que estiveram em contato com o paciente deverão realizar higiene corporal e as roupas privativas deverão ser trocadas. Somente cirurgias de urgência e emergência deverão ser realizadas durante o período crítico da pandemia ${ }^{(1,9)}$.

Para evitar movimentação desnecessária de pacientes com suspeita ou infectados e dos profissionais envolvidos na assistência anestésico-cirúrgica, o paciente deverá ser avaliado e recuperado dentro da sala cirúrgica que foi designada para tal ${ }^{(9)}$.

Durante a anestesia, todas as medidas para manter a segurança do paciente e impedir a propagação da infecção devem ser tomadas. Sabendo-se que as manipulações das vias aéreas de pacientes infectados e com suspeita de infecção podem gerar aerossóis, deve-se evitar qualquer manipulação desnecessária, ventilação com pressão positiva sob máscara facial, aspiração com circuito aberto e tosse do paciente durante a intubação ou extubação traqueal ${ }^{(3,7)}$.

Se for possível realizar anestesia regional, deve-se manter o paciente com máscara cirúrgica durante o procedimento. Se for indicada oxigenação suplementar nos pacientes que não estão intubados, deve-se usar cateter nasal simples sob a máscara cirúrgica, sendo contraindicados cateteres de alto fluxo ou ventilação não-invasiva ${ }^{(11)}$.

\section{Fluxo de Atendimento no Período Pe- rioperatório}


Com o fim de prestar uma assistência cirúrgica segura em tempos de pandemia, as unidades de saúde deverão aderir a protocolos visando condutas para prevenção e controle de transmissão do SARS-COV2, dentro dos centros cirúrgicos ${ }^{(12,3)}$.

Considerando a necessidade de ter uma sala exclusiva para procedimentos de pacientes com a Covid-19 e com recomendações restritas a este tipo de atendimento é necessário que toda equipe esteja apta a prestar tal assistência. Para isso faz-se necessário que a equipe de enfermagem estabeleça protocolos para o atendimento, para classificação de casos suspeitos ou confirmados e diretrizes dos fluxos a serem realizados durante a assistência perioperatório ${ }^{(13)}$.

Os profissionais deverão ser preparados para tal atendimento, através de capacitações, treinamentos e simulações de atendimento. Com isso, poderão prever possíveis conflitos e estruturar estratégias para um melhor atendimento, se sentindo seguros e confiantes nos eventos adversos ${ }^{(3)}$.

Todos os membros dentro da sala operatória se tornam mais suscetível ao vírus, pelo contato, gotículas e aerossóis gerados na preparação e procedimentos realizados. Portanto, podem se tornar veículos de transmissão. Então é recomendado que seja limitado o período de exposição do profissional ao paciente. Diante disso faz se necessário que seja considerado que somente permaneçam os profissionais essenciais no procedimento cirúrgico, evitarem a troca destes durante o processo e que de preferên- cia sejam os profissionais mais experientes no atendimento ${ }^{(3,7,13,14)}$.

No período de intubação e extubação devem permanecer na sala somente os profissionais necessários e a equipe cirúrgica ficar fora da sala até estabelecer uma via aérea segura. Inclusive, disponha de um profissional circulante fora da sala operatória para providenciar materiais necessários no momento do procedimento cirúrgico ${ }^{(3,12)}$.

Importante também, determinar antes do procedimento um fluxo de transferência do paciente pela unidade hospitalar e as precauçóes tomadas de proteção com a equipe transportadora. Esta deverá receber o paciente com os EPI e o mesmo deverá seguir diretamente para sala operatória. Portanto, as intervençôes de enfermagem realizadas no planejamento do fluxo de atendimento se mostram importantes visando prevenir o contágio e proliferação da Covid-19 ${ }^{(7,13)}$.

\section{Monitoramento Saúde Ocupacional}

Os profissionais do centro cirúrgico também estão com alto risco de exposição ao vírus, devido estar em contato próximo com o paciente e através de procedimentos realizados que podem gerar partículas contaminadas, visto que alguns pacientes podem ser potencialmente transmissores durante estes procedimentos ${ }^{(13,15)}$.

Deste modo é importante a implantação de ações visando à segurança do profissional na prevenção, monitoramento, afastamento, tratamento dos profissionais expostos durante suas atividades e também visando garantir que os mesmos não se tornem fonte de propagação em seu meio ${ }^{(16,17)}$.

Os serviços de saúde devem promover monitoramento de maneira individual ou conjunta para este fim, em acordo com comissão de controle de infecção hospitalar, núcleo de segurança, enfermagem do centro cirúrgico, gestores e as equipes que trabalham no setor ${ }^{(16,17)}$.

Estratégias essas que podem ser passivas: através da autoavaliação quanto à presença de sinais e sintomas, sendo orientado na presença comunicar a chefia, receber logo a avaliação médica e manter afastado de suas atividades laborais, conforme as orientações do Ministério da Saúde. Ou ativas: através de avaliação diária antes de cada turno de trabalho; e estratégia ativa remota: todos os profissionais reportam remotamente a presença ou ausência de sintomas diariamente ${ }^{(17)}$.

De acordo com essas avaliações o profissional que apresentar Síndrome Gripal ou Síndrome Respiratória Aguda Grave (SRAG) ou tenha algum contato próximo domiciliar nestas condições deverão comunicar a chefia, ser avaliados e afastados imediatamente do trabalho ${ }^{(17,18)}$.

Sem dúvida, todos os cuidados com os profissionais são necessários para garantir que os procedimentos não sejam interrompidos, não se tornem cadeia de transmissão e trabalhem de forma tranquila e segura visando à redução dos impactos negativos da Covid-19(16,17).

Quadro 2. Afastamento de profissionais de serviços de saúde suspeitos ou confirmados e retorno de suas atividades.

\begin{tabular}{|c|c|}
\hline TESTE & AÇÕES DO AFASTAMENTO \\
\hline Assintomáticos não gravemente imunossuprimidos & $\begin{array}{l}10 \text { dias após a data do primeiro teste RT-PCR em tempo real } \\
\text { Positivo e com avaliação médica atestando a segurança no seu retorno. }\end{array}$ \\
\hline $\begin{array}{l}\text { Pacientes assintomáticos e gravemente } \\
\text { imunossuprimidos }\end{array}$ & $\begin{array}{l}\text { Pelo menos } 20 \text { dias desde o primeiro teste RT-PCR em tempo } \\
\text { real positivo e com avaliação médica atestando a segurança no seu retorno. }\end{array}$ \\
\hline $\begin{array}{l}\text { Pacientes com quadro leve a moderado, não gravemente } \\
\text { imunossuprimidos }\end{array}$ & $\begin{array}{l}\text { Pelo menos } 10 \text { dias desde o início dos sintomas E pelo menos } 24 \\
\text { horas sem febre (sem uso de antitérmicos) E melhora dos sintomas }\end{array}$ \\
\hline $\begin{array}{l}\text { Pacientes com quadro grave/crítico OU gravemente } \\
\text { imunossuprimidos }\end{array}$ & $\begin{array}{l}\text { Pelo menos } 20 \text { dias desde o início dos sintomas E pelo menos } 24 \text { horas sem } \\
\text { febre (sem uso de antitérmicos) E melhora dos sintomas }\end{array}$ \\
\hline TESTE INDISPONIVEL & $\begin{array}{l}\text { - Mínimo de } 72 \text { horas assintomático E } \\
\text { - Mínimo de } 7 \text { dias após o início dos sintomas. }\end{array}$ \\
\hline
\end{tabular}


Cuidados de Enfermagem Durante o Atendimento a Pacientes Sintomáticos / Suspeitos.

Os profissionais de enfermagem que estão da linha de frente no combate e controle da propagação do novo coronavírus representam a maior categoria atuante na área de saúde, seja em instituições públicas ou privadas, e são os únicos profissionais presentes na assistência direta 24 horas por dia junto aos pacientes. Estando muito mais suscetíveis à infecção devido a sua atuação no acolhimento, o atendimento humanizado, a detecção e avaliação das situações suspeitas de contágio do coronavírus e à capacidade técnica deste profissional ${ }^{(19)}$.

A recomendação da Agência Nacional de Vigilância Sanitária (ANVISA) de medidas consideradas obrigatórias a serem implementadas para prevenção e controle da disseminação do vírus nos serviços de saúde por profissionais de saúde são: higiene das mãos com água e sabonete líquido ou preparação alcoólica a $70 \%$; e os equipamentos de proteção individuais (EPI), óculos de proteção ou protetor facial (face shield), máscara cirúrgica, avental, luvas de procedimento, máscara cirúrgica, máscara N95/PFF2 e gorro ${ }^{(19)}$.

Medida fortemente adotada tem sido a higienização das mãos, preferencialmente com água e sabão, por meio de movimentos de fricção que contemplem as palmas das mãos e os dedos, inclusive friccionando separadamente polegares, pontas dos dedos e punhos. As mãos devem ser lavadas obrigatoriamente entre os atendimentos a diferentes pacientes, após a finalização de cada atendimento e antes de retirar máscaras N95 e óculos. Diante da impossibilidade de lavá-las, preparações alcoólicas a $70 \%$ podem ser utilizadas. Sugere-se colocar uma quantidade moderada nas mãos e friccioná-las com os mesmos movimentos da lavagem com água e sabão, pois é a fricção que garante a limpeza. Aplicar grande quantidade do produto sem fricção não produz o efeito esperado ${ }^{(20)}$.

A equipe de enfermagem deverá trocar a máscara cirúrgica por uma máscara N95/PFF2, ao realizar procedimentos geradores de aerossóis, como por exemplo: auxiliar em intubação ou aspiração traqueal, ventilação mecânica não invasiva, ressuscitação cardiopulmonar, ventilação manual antes da intubação, coletas de amostras nasotraqueais, broncoscopias, entre outros. A Norma Regulamentadora NR32 orienta que profissionais de enfermagem estão expostos a riscos biológicos, e considera como risco biológico a probabilidade da exposição ocupacional a agentes biológicos e determina em seu Art. 32.2.4.7 que os EPI devem estar disponíveis em número suficiente, nos postos de trabalhos, garantindo o imediato fornecimento ou reposição para todos os profissionais ${ }^{(19)}$.

Além disso, os serviços de saúde devem fornecer capacitação para todos os profissionais de saúde (próprios ou terceirizados), realizando a prática do uso apropriado de todos os EPI antes de cuidar de um caso suspeito ou confirmado de infecção pelo novo coronavírus, incluindo a atenção ao uso correto de EPI, testes de vedação da máscara N95/PFF2 ou equivalente (quando for necessário o seu uso) e a prevenção de contaminação de roupas, pele e ambiente durante o processo de remoção de todos os equipamentos ${ }^{(19)}$.

\section{CONCLUSÃO}

Neste trabalho discutimos a assistência de enfermagem no centro cirúrgico no cuidado com paciente suspeito/confirmado com SARS-COV2. Contextualizamos ações a serem elaboradas e trabalhadas em toda a assistência, visando prestar um atendimento com segurança para os trabalhadores e pacientes assistidos.

Dessa forma, buscamos encorajar os profissionais da enfermagem a fortalecer o elo entre todos os envolvidos na unidade do centro cirúrgico através de protocolos e treinamentos, com o propósito de realizar um procedimento seguro e um trabalho realizado em equipe pautado na confiança, comprometimento e técnica. Compreendemos a importância do engajamento de todas as equipes e na realização de cada processo do atendimento ao paciente suspeito/confirmado, a fim de evitar risco e contaminação dos profissionais e pacientes.

Enfim, diante da pandemia todas as equipes nas unidades cirúrgicas passaram por adaptações e aumentaram ainda mais seu cuidado com as tarefas realizadas, mas a enfermagem mesmo com tantos desafios no dia a dia, destaca como sendo ainda aqueles profissionais que visam sempre o cuidado mais amplo, cuidar voltado para o bem estar do próximo ligando conhecimento, experiência e empatia. -

\section{REFERÊNCIAS}

1. Brasil. Ministério da Saúde (Brasil). Protocolo de Manejo Clínico para o Novo Coronavírus (2019-nCoV). Brasília: Ministério da

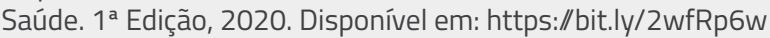

2. Organização Pan Americana de Saúde (OPAS\OMS, 2020) [acesso em 1 maio 2020]. Disponivel em: https://www.paho.org/ bra/index.php?option=com_content\&view=article\&id=6130:covid-19-materiais-de-comunicacao\&Itemid=0

3. Agência Nacional de Vigilância Sanitária (Brasil). Nota Técni- ca GVIMS/GGTES/ANVISA n 06/2020. Orientações para a prevenção e o controle das infecções pelo novo coronavírus (sarscov-2) em procedimentos cirúrgicos - revisão: 29.05.2020. [acesso em 15 junho 2020], Disponivel em: http://portal.anvisa. gov.br/documents/33852/271858/Nota+ t\%C3\%A9cnica+062020+GVIMS-GGTES-ANVISA/40edaf7d-8f4f-48c9-b876bee0090d97ae.

4. Possari JF. Centro Cirúrgico: Planejamento, Organização e 
Gestão. $5^{a}$ edição. São Paulo: Látria; 2011.

5. Coimbra R, Edwards S, Kurihara H, Bass GA, Balogh ZJ, Tilsed J. etal. European Society of Trauma and Emergency Surgery(ESTES) recommendations for trauma and emergency surgery preparation during times of COVID-19 infection. Eur J Trauma Emerg Surg. [internet] 2020 [acesso em 01 julho 2020]; 46(3):50510. doi:10.1007/s00068-020-01364-7. Disponivel em: https:// link.springer.com/search?query=European+ Society+of+Trauma+and+Emergency+surgery+\%28ESTES\%29+recommenddations+for+trauma+and+emergency+surgery+preparation+during+times+of+COVID\%E2\%80\%9119+infection\&search-within=Journal\&facet-journal-id=68.

6. Mendes KDS, Silveira RCCP, Galvão CM. Uso de gerenciador de referências bibliográficas na seleção dos estudos primários em revisão integrativa. Texto Contexto Enferm [Internet]. 2019 [acesso em 7 de setembro 2020]; 28:e20170204. Disponível em: https://dx.doi.org/10.1590/1980-265X-TCE-2017-0204

7. Associação Brasileira de Enfermeiros de Centro Cirúrgico, Centro Esterilização e Recuperação Anestésica (SOBECC). Recomendações relacionadas ao fluxo de atendimento para pacientes com suspeita ou infecção confirmada pelo covid-19 em procedimentos cirúrgicos ou endoscópicos. 2 ed. [Internet]. 2020. [acesso em 11 maio 2020]; Disponível em: http://sobecc. org.br/arquivos/RECOMENDACOES_SOBECC_COVID_2o_EDICAO_NOVO_LOGO.pdf.

8. Anvisa (Brasil). Nota Técnica nº 0 /2020 GVIMS/GGTES/ANVISA BRASIL. Orientações para serviços de saúde: medidas de prevenção e controle que devem ser adotadas durante a assistência aos casos suspeitos ou confirmados de infecção pelo novo coronavírus (covid-19). Atualizada em 27/10/2020. [acesso em 27 de outubro 2020], Disponivel em: https://www20.anvisa.gov. br/segurancadopaciente/index.php/alertas/item/nota-tecnica-n-04-2020-gvims-ggtes-anvisa-atualizada.

9. Souza JM, Santos RS. POP.UVS.001. Unidade de Vigilância em Saúde do HU-UFPI - Paramentação e desparamentação no atendimento à pacientes com suspeita/confirmação de covid-19. [Internet]. 2020 [acesso em 15 de junho 2020]

10. Wong J, Goh QY, Tan Z, Lie SA, Tay YC, Ng SY, et al. Preparing for a COVID-19 pandemic: a review of operating room outbreak response measures in a large tertiary hospital in Singapore. Can J Anesth/J Can Anesth 67, 732-45 (2020). [acesso em 15 julho 2020]. Disponivel em: https://doi.org/10.1007/s12630-02001620-9

11. Orientações em casos suspeitos ou confirmados de infecção por Covid-19. [Accamargo] [acesso em 15 julho 2020]. Disponível em: http://www.accamargo.org.br/sites/default/files /2020-04/ CC_TT_-_Recomendacoes_COVID-19_2020_04_27_V3.pdf

12. Colégio Brasileiro de Cirurgiões. Orientações para o retorno de cirurgias eletivas durante a pandemia de COVID19. [CBC] [acesso em 2 agosto 2020]. Disponivel em: https://cbc.org. br/wp-content/uploads/2020/05/PROPOSTA-DE-RETOMADA-DAS-CIRURGIAS-ELETIVAS-30.04.2020-REVISTO-CBCAMIBSBASBOT-ABIH-SBI-E-DEMAIS.pdf.
13. Kang $Y$, Deng $L$, Zhang $D$, Wang $Y$, Wang $G$, Mei $L$, et al. $A$ practice of anesthesia scenario design for emergency cesarean section in patients with COVID-19 infection based on the role of standard patient. Biosci Trends. [revista internet] 2020 Jul 17;14(3):222-226. [acesso em 2 agosto 2020]. Disponível: doi: 10.5582/bst.2020.03066. Epub 2020 Apr 22. PMID: 32321903.

14. Lockhart SL, Duggan LV, Wax RS, Saad S, Grocott HP. Personal protective equipment (PPE) for both anesthesiologists and other airway managers: principles and practice during the COVID-19 pandemic. Can J Anaesth. [revista internet] 2020 Aug;67(8):1005-1015. [acesso em 15 agosto 2020]. doi: 10.1007/s12630-020-01673-w. Epub 2020 Apr 23. PMID: 32329014; PMCID: PMC7178924.

15. Coffey S, Moynagh A, Green B, Edmond J, Wilkins GT, Pemberton J, et al. Changes to management of a non-pandemic illness during the COVID-19 pandemic: case study of invasive management of acute coronary syndrome. N Z Med J. [revista internet] 2020 Apr 24;133(1513):101-106. PMID: 32325474. [acesso em 15 agosto 2020]. Disponivel em: www.nzma.org.nz/journal

16. Gallasch CH, Cunha ML, Pereira LAS, Silva-Junior JS. Prevenção relacionada à exposição ocupacional: COVID-19. [Rev enferm UERJ]. Disponível em: DOI: http://dx.doi.org/10.12957/ reuerj. 2020.49596

17. Agência Nacional de Vigilância Sanitária (Brasil). Nota Técnica GVIMS/GGTES/ANVISA n 07/2020. Orientações para a prevenção da transmissão de covid-19 dentro dos serviços de saúde. [acesso em 10 setembro 2020], Disponível em: https:// www20.anvisa.gov.br/Segu rancadopaciente/index.php/alertas/item/nota-tecnica-gvims-ggtes-anvisa-n-07-2020 ?cat egory_id $=244$

18. Ministério da Saúde (Brasil). Guia prático de gestão em saúde no trabalho para covid-19. Brasília: Ministério da Saúde. $1^{a}$ Edição, 2020. Disponível em: Disponível em: https://www.abrasco.org.br/site/wp-content/uploads/2020/07/Guia-Pra\%CC\%81tico-de-Gesta\%CC\%83o-em-Sau\%CC\%81de-no-Trabalhopara-COVID-19_20-07-20-1.pdf

19. Marques LC, Lucca DC, Alves EO, Fernandes GCM, Nascimento KC. Covid-19: cuidados de enfermagem para segurança no atendimento de serviço pré-hospitalar móvel. Texto Contexto Enferm [Internet]. 2020 [acesso em 14 de setembro 2020]; 29:e20200119. Disponivel em: https://doi.org/10.1590/1980265X-TCE-2020-0119

20. Oliveira PCC. Pandemia do novo coronavírus (SARS-CoV-2): panorama do enfrentamento dos profissionais de enfermagem no controle de infecção pela doença COVID-19 no Brasil. Texto Contexto Enferm [Internet]. 2020 [acesso em 14 de setembro 2020]; DOI: https://doi.org/10.36489/saudecoletiva.2020v10i54p2691-2698.

21. Ministério da Saúde (Brasil). Boletim Epidemiológico Especial. Doença pelo Coronavírus COVID 19. Versão 1, 3 de Dezembro 2020. Disponível em: Disponivel em: https://www.gov.br/ saude/pt-br/media/pdf/2020/ dezembro/03/boletim_epidemiologico_covid_39.pdf 